Revista Iberoamericana, Vol. LXX, Núm. 206, Enero-Marzo 2004, 73-86

\title{
A ESCRAVA ISAURA: LA JUSTICIA DIVINA COMO GARANTÍA ENTRE EL ORDEN PÚBLICO Y EL PRIVADO
}

\author{
POR \\ Ana Miramontes \\ University of Pittsburgh
}

En 1875, la Casa Garnier de Río de Janeiro publica A escrava Isaura, que se suma a otras novelas de Bernardo Guimarães, también poeta y autor de Lendas e Romances (1871) y de História e tradições da Provincia de Minas Gerais (1872). Allí, en Minas Gerais, su tierra natal, se desempeñó además como juez, catedrático y periodista. Dentro de la amplia producción literaria de Bernardo Guimarães, A escrava Isaura ha sido, sin lugar a dudas, la obra que a través del tiempo alcanzó mayor popularidad. ${ }^{1}$

La novela relata las desventuras de la mulata Isaura, una esclava con apariencia de blanca, que vive en una hacienda situada cerca de Río de Janeiro donde lleva una existencia muy diferente a la de los otros esclavos que están en la senzala. Isaura ha sido educada con el refinamiento propio de una joven de buena posición, debido a los recaudos tomados por su difunta ama, esposa del Comendador. El nuevo heredero del Comendador, amo y señor de la hacienda y de todos sus esclavos, es Leôncio quien siente por Isaura una pasión irrefrenable e intenta desesperadamente obtener sus favores, a pesar de estar casado con Malvina, quien por su parte siente por Isaura la misma simpatía que su difunta suegra. Con la ayuda de su padre, el administrador (feitor) de la hacienda, Isaura logra huir de Leôncio y llega a Recife donde intenta ocultar su identidad. Allí conoce a Álvaro, joven republicano y liberal que se enamora de ella e intenta rescatarla de las garras de Leôncio, quien de todos modos acaba por encontrarla y llevarla otra vez a la hacienda. El enfrentamiento entre ambos caballeros concluye con la victoria final de Álvaro que obtiene la libertad y el amor de Isaura, tras precipitar la ruina económica de Leôncio, quien finalmente se suicida.

La producción de Guimarães se inscribe dentro de lo que se conoce como la segunda generación romántica, caracterizada por una literatura con acentuados trazos de realismo, algo de lo que, sin embargo, adolece A escrava Isaura, según Antonio Candido. Sostiene el crítico que, a diferencia de otras de sus novelas, este relato se basa en personas y lugares que son ajenos a la experiencia de Guimarães (por ejemplo, la lujosa hacienda en Recife),

${ }^{1}$ La novela fue reeditada decenas de veces y también llevada al cine en dos oportunidades: la primera en 1929, la segunda en 1949. En 1976 fue adaptada para televisión y difundida a través de la Rede Globo con un enorme éxito de público a nivel nacional e internacional. Fue vista por millones de telespectadores en sesenta países de todo el mundo (en toda América Latina, China, Rusia, Sudáfrica, Alemania, Francia, etc.) incluso veinte años después de su lanzamiento. http:// www.geocities.com/Athens/Olympus/3583/premiere.htm) 9/05/2001 
y que su falta de realismo malogró una novela que por su asunto hubiera requerido precisamente lo contario, con lo cual el relato acaba siendo sumamente esquemático (24243). ${ }^{2}$ No obstante -agrega Candido- lo que consagra a este libro es su alcance humano y social, para lo cual es preciso tomar en cuenta la situación de Brasil en aquella época,

destacando-o como panfleto corajoso e viril, que pôs em relêvo ante a imaginação popular situações intoleráveis do cativeiro. Numa literatura tão aplicada quanto a nossa, não é qualidade desprezível. Tanto mais quanto o romancista timbrou em passar da descrição à doutrina, pondo na bôca de personagens (sobretudo na parte decorrida em Recife) tirades e argumentos abolicionistas. (243, énfasis del autor)

Lo cierto es que la novela se publica en plena campaña abolicionista, cuatro años después de la sanción de la Ley de Libertad de Vientres (1871) que sirvió de prolegómeno a la abolición de la esclavitud en 1888, desencadenante de la crisis socioeconómica que precipitó la caída de la monarquía al año siguiente. A pesar de cierto tono crítico empleado por Guimarães para referirse a la esclavitud, los argumentos abolicionistas de los que habla Candido quedan de algún modo relativizados por la construcción misma del relato que los acoge. Prefiero entonces remitirme a estudios más recientes que permiten una caracterización más apropiada del libro de Guimarães en términos de “(anti)esclavismo figurado” (Rosell 157). Al respecto, afirma Sara V. Rossell: “si bien es cierto que la novela cae dentro de la literatura antiesclavista, por el hecho de atacar la institución, cabe señalar que lo hace desde el punto de vista integracionista y no desde el punto de vista pro-africano/negrista" (157). ${ }^{3}$

Como tantas novelas latinoamericanas del siglo XIx, A escrava Isaura se publica en el contexto del surgimiento y consolidación de los estados nacionales impulsados por las burguesías locales. Puede, entonces, ser leída desde las perspectivas críticas que consideran la literatura del período como un discurso que se interrelaciona con otros (las ciencias, la historia, la política, y la economía) y desde el cual las élites intelectuales proyectan o ficcionalizan su idea de nación como comunidad imaginada (Anderson). Como se sabe, Doris Sommer retoma la línea crítica abierta por Benedict Anderson y la del análisis de la ficción moderna que hace Nancy Armstrong, quien reconoce el ámbito doméstico (privado, femenino) como marco del deseo y la sexualidad que pretenden regularse desde

${ }^{2}$ Del mismo modo que Antonio Candido define a Guimarães como “um contador de casos”(236), también Afranio Coutinho prefiere considerarlo "mais contador de historias do que romancista" (270-71) y amplía esta idea diciendo que "Bernardo Guimarães tem, na realidade, uma concepção primária de romance, em conseqüencia da influência dominadora que nele exerceu a literatura oral" (270).

${ }^{3}$ En La novela antiesclavista en Cuba y Brasil, siglo XIX, Sara V. Rossell lleva a cabo un estudio comparativo entre la novela de Guimarães y Úrsula (1859) de Maria Firmina dos Reis, una autora que permaneció desconocida en Brasil hasta la década de 1970. Maria Firmina dos Reis fue una mujer mulata que se dedicó al magisterio y a la literatura, lo que sumado a sus ideas abolicionistas le valió la marginalización extrema, junto con su exclusión de la historia de la literatura. Para el caso cubano, Rosell incluye en su estudio: Sab (1841) de Gertrudis Gómez de Avellaneda y Cecilia Valdés o La Loma del Ángel (edición de 1882) de Cirilo Villaverde. 
el ámbito público (masculino). Desde este cruce, Sommer postula una dialéctica del deseo -reconocible en tantos "romances" fundacionales de las naciones latinoamericanas- en la que uno y otro nivel (Eros y Polis) se refuerzan mutuamente.

So it is not only desire that doubles itself on public and private levels here; it is also the public obstacle that deters (and goads) the erotic and national projects. Once the couple confronts the obstacle, desire is reinforced along with the need to overcome the obstacle and to consolidate the nation. That promise of consolidation constitutes another level of desire and underscores the erotic goal, which is also a microcosmic expression of nationhood. (Sommer 49)

En mi lectura de A escrava Isaura consideraré el funcionamiento de estos dos órdenes, público y privado, en torno al deseo amoroso del triángulo constituido por Isaura, Álvaro y Leôncio. Desde su condición de mujer mulata que parece blanca, Isaura se torna en un elemento altamente significativo dentro del relato. En otras palabras, si no merece ser esclava es porque reúne todos los atributos de una mujer blanca con acceso a la educación y con todas las virtudes del "ángel del hogar”, y no porque la esclavitud se condene totalmente. Este "blanqueamiento" de Isaura implica analizar las relaciones entre raza, esclavitud y ciudadanía en el Brasil del siglo xIX. Para ello tomaré en cuenta el contexto histórico al que remiten tanto la publicación de la novela (1875) como los hechos narrados, es decir comienzos del reinado de Pedro II, quien gobernó Brasil entre 1840 y 1889. Desde ese contexto pueden leerse las ambivalencias propias de una intelectualidad que no termina de definir claramente su entrada a una modernidad resistida por las instituciones del viejo orden patriarcal y latifundista. En mi lectura, propongo que estas instituciones persisten en el reclamo de una justicia divina que garantice el derecho de propiedad (sobre los bienes y los cuerpos) en lugar de la marcada secularización a la que aspiraban los estados nacionales modernos.

En un artículo sobre las ideas raciales en Brasil, Thomas Skidmore comenta que el censo de 1872 registró un 38\% de la población como blanca, un 20\% como negra, y el resto fue clasificado como mulato. Ya por entonces existía un amplio número de afrobrasileños libres, en su mayoría mulatos pero también negros. No existe pleno acuerdo entre los historiadores acerca de cómo estas personas llegaron a ser libres (ya sea porque la relación numérica no favorecía a los blancos y convenía 'amortiguar' esa diferencia facilitando el surgimiento de un sector intermedio dentro de la sociedad, o porque la corona y la Iglesia alentaran en alguna medida, la manumisión), lo cierto es que algunos de ellos, como Rebouças, llegaron incluso a ocupar cargos de importancia en la corte imperial. (Skidmore 8). ${ }^{4}$

\footnotetext{
${ }^{4}$ Por su parte, en Brazil Empire and Republic. 1822-1930, Leslie Bethell aporta la siguiente información: "Durante el siglo xix hubo importantes cambios demográficos en Brasil. La población creció de 3,8 millones en 1822 a poco más de 10 millones en 1872, y llegó a más de 14 millones para la época en que se proclama la República en 1889. [...] Los esclavos, que constituían más de la mitad de la población en 1822 y el 15,8\% en 1872, representaban apenas el 5\% en 1888. La población esclava disminuyó en las ciudades y llegó a concentrarse en las áreas de plantación donde la economía se estaba expandiendo. En 1822, casi el 70\% vivía en las áreas de la caña de azúcar del
} 
El discurso presuntamente científico sobre la "raza”, que partiendo de diversas teorías (la etnológica-biológica del poligenismo, la histórica de Gobineau, y el darwinismo social) comienza a generarse en Europa y Estados Unidos hacia mediados del siglo XIX, solo alcanza verdadera repercusión en Brasil tardíamente, después de la abolición de la esclavitud. Según Skidmore, “en el fondo, nadie creía en la simple teoría de la inferioridad biológica, por lo tanto los abolicionistas rara vez trataron de refutar las doctrinas racistas. Incluso, los defensores de la esclavitud argüían más bien razones de tipo económico, al considerarla un mal necesario, y también encontraban que sus esclavos eran físicamente superiores a muchos trabajadores libres de Europa”(8). Sin embargo, agrega Skidmore, el tema de la raza en Brasil empieza a perfilarse como una preocupación por el "blanqueamiento" aunque no en términos fisiológicos sino culturales. El color atribuido a un individuo adquiría una función en relación con su posición dentro de la sociedad y por eso el mestizaje (miscegenation) era considerado como regenerativo, no en términos biológicos sino de contacto cultural (9). ${ }^{5}$

Por su parte, Sara V. Rosell, sostiene que este proceso de blanqueamiento -que se articula como tal en el siglo xx, aunque ya se anticipe desde el XIX-aparece ligado a la preocupación por el color de la piel, lo que da lugar a un discurso de(r)mográfico "que constituye la base de las manifestaciones económicas, políticas y culturales en ambas sociedades [Cuba y Brasil] y que esto constituye la base ideológica en la conformación de la nación y de la literatura nacional” (17). Esto tendría, según Rosell, un doble efecto: por un lado, intenta crear en la raza negra la necesidad de llegar a ser como el blanco, y esto "no sólo libra a la clase dominante de sus responsabilidades, sino que imposibilita al sector negro de contener [sic] una agenda política para tratar su situación” (17). De este modo podemos ver cómo en la novela de Guimarães "se ficcionaliza el blanqueamiento. Isaura — hija de un portugués y de una esclava mulata — presenta la perspectiva de una mujer esclava que, en términos biológicos, sicológicos y culturales ha perdido el origen” (19), y en esto se opone a Úrsula la novela de Maria Firmina dos Reis, donde sí se advierte "un intento por mantener el color y la cultura negra en lugar de caer en el discurso asimilista” (177), pero precisamente por eso, como ya se ha dicho (ver nota 3), esta novela no formó parte de la historia literaria brasileña.

nordeste y del este. Sesenta años después, sólo el 35\% de la población esclava total vivía allí, mientras que el 65\% estaba en las provincias cafeteras del sur” (164). [Esta traducción y las que aparezcan de aquí en adelante me pertenecen].

${ }^{5}$ Thomas Skidmore analiza en detalle el "blanqueamiento" como idea racial y explica que: "The whitening thesis got unique support in Brazil from the widespread belief, later popularized by Gilberto Freyre, that the Portuguese enjoyed an uncanny ability to whiten the darker peoples with whom they mixed. At times, this view seemed almost to amount to a faith in the 'strong' genes of the amorous Portuguese. Underlying the belief was a largely unverified conclusion that black and mulatto net reproduction was low. Often this phenomenon was attributed to allegedly low fertility among blacks or mulattoes. In any case, it was taken as comforting proof that Brazil's color problem would gradually and inevitably dissapear. As European immigrants increased the white element, the darker strain would naturally fade either through miscegenation or thorugh failure to reproduce”(9$10)$. 
Esta idea del “color” como dato significativo aparece en los primeros censos de la época imperial, y genera protestas en la población, como lo prueba el siguiente fragmento publicado en 1833 en un periódico liberal denominado O Mulato o O Home de Cor:

Não sabemos o motivo por que os brancos moderados nos hão declarado guerra. Há pouco lemos uma circular em que se declara que as listas dos Cidadãos Brasileiros devem conter a diferença de cor -e isto entre homens livres! (Mattos 22)

Sin embargo, tal como lo explica Hebe Maria Mattos, “esta igualdad entre los ciudadanos libres reivindicada por las poblaciones libres 'de color' implicaba, antes que nada el silenciamiento sobre el propio color” (22). Esto se explica, según Mattos, porque “la igualdad que se reivindicaba para los ‘ciudadanos libres' no implicaba -sea del punto de vista de las reivindicaciones populares, sea como corolario lógico de su formulación con base en el pensamiento liberal — ninguna proposición efectiva a favor de la abolición inmediata de la esclavitud" (23-4, énfasis de la autora), debido, sobre todo, a que la esclavitud permanecía anclada fundamentalmente al derecho de propiedad, el que a su vez aseguraba derechos políticos. Así lo garantizaba la Constitución de 1824, que además había reconocido y legitimado privilegios señoriales y jerarquías sociales heredados del imperio portugués.

Por lo tanto, a pesar de las proclamas de libertad que traen los albores independentistas del siglo xix, en un país marcadamente esclavista como Brasil, la sola enunciación de la palabra "libertad" presuponía un dilema para la élite dominante, sumado a los riesgos de que finalmente "las discusiones sobre libertad e igualdad [...] fuesen apropiadas por las senzalas en un contexto de posible alianza entre la gente de color, proponiendo la abolición de la esclavitud y masacrando a los blancos, como en Haití”(Mattos 27-8). Lo cierto es que, por ese entonces, ni liberales ni conservadores, esgrimen la cuestión de la "raza” como argumento cientificista, a diferencia de lo que sí ocurría en Estados Unidos, “donde la legitimación de la continuidad de la esclavitud tendía rápidamente a adoptar una perspectiva marcadamente racial” (Mattos 46). Lo que se busca en definitiva es cómo legitimar la paradoja que la esclavitud suscita dentro del marco de la modernidad. Tal como sostiene Carol Pateman en The Sexual Contract, los propietarios de esclavos en Estados Unidos en algún momento creyeron superar la paradoja de la esclavitud, argumentando que "los servicios, capacidades y fuerza de trabajo podían separarse de la persona” (72) y sobre éstos -no sobre la persona del esclavo- se ejercía el derecho de propiedad. La cuestión era cómo, en la práctica, podían separarse una cosa de la otra, cuando lo que en realidad se ejercía era la propiedad sobre personas que no podían “contratar” libremente sus servicios. Volviendo a Brasil, las prácticas segregacionistas de los Estados Unidos fueron criticadas por Antônio Pereira Rebouças, figura clave en la escena política de la época, quien precisamente se empeña en “desracializar” la institución de la esclavitud, en un debate público de 1832 sobre los derechos de ciudadanía de los libertos. ${ }^{6}$ Su abierta oposición a la discriminación ejercida sobre quienes no habían nacido

\footnotetext{
${ }^{6}$ Antônio Pereira Rebouças, nacido en Bahía en 1798, era hijo de una liberta y de un sastre portugués. Autodidacta, llega a ser abogado, especialista en derecho civil, Consejero del Emperador y abogado
} 
libres no implica, sin embargo, un ataque abierto a la esclavitud, respecto a cuya continuidad se muestra tolerante. La base de su argumentación es jurídica y se ubica en el campo de las libertades civiles defendidas por el liberalismo. Desde su perspectiva "las jerarquías sociales deberían ser formadas a partir de ‘virtudes y talentos’ y la capacidad para adquirir propiedades era el principal índice de las realizaciones de que esas 'virtudes y talentos' eran capaces” (Mattos 46-7). Esta legitimidad de la esclavitud basada en el derecho de propiedad adquirida llevaba a que la autocompra fuese transformada en ley, y tal fue el reclamo de Rebouças años después, en 1859. Esto sólo tendría estatus legal a partir de 1871, con la Ley de Libertad de Vientres. Dicho sea de paso, recordemos que en la novela de Guimarães la acción se mueve precisamente en torno al hecho de que en varias ocasiones Isaura parece estar a punto de obtener su libertad: la madre de Leôncio le brinda una educación con la esperanza de que algún día obtenga su libertad; pero al morir ella, su esposo, el Comendador fija un precio demasiado alto a esa libertad, previendo que el padre de Isaura no lograría reunir la suma; también Henrique, el cuñado de Leôncio se ofrece a comprarla, y a su vez éste le ofrece la libertad con la condición de que ceda a sus deseos. Finalmente la ruina económica de Leôncio, de la que Álvaro saca ventaja para adquirir sus bienes -incluida Isaura- permite a éste, como nuevo propietario, ceder la propiedad de Isaura a la propia interesada, puesto que a él lo impulsa la firme convicción de que

[...] o céu, pondo em contato o seu destino com o daquela encantadora e infeliz escrava, tivera um desígnio providencial, e o escolhera para instrumento da nobre e generosa missão de arrebatá-la à escravidão, e dar-lhe na sociedade o elevado lugar que por sua beleza, virtudes e talentos, lhe competia. (152, énfasis mío)

Como se ve, las ‘virtudes y talentos’ a las que se refería Antônio Pereira Rebouças -desde un elitismo liberal-son las que convierten a Isaura en merecedora de su libertad, y si la iniciativa de tal empresa corresponde a Álvaro es por obra de la Divina Providencia. Creo que en el párrafo precedente puede hallarse una clave de lectura de la novela en términos de la actitud ambivalente que la intelectualidad brasileña de la época adoptó frente al tema de la esclavitud, incluso desde un liberalismo que se revela sumamente contradictorio. Dejando de lado por el momento el factor "divino" introducido por Guimarães -como resabio de un discurso del viejo orden conservador- vemos que es precisamente la formación liberal de ciertos intelectuales -como Rebouças y Luís Gamala que los lleva, según Mattos, a “desracializar” la legitimidad de la esclavitud (58). De ahí que pueda leerse una coherencia en los reclamos de Rebouças ante el incumplimiento de la ley que en 1831 prohibía el tráfico de esclavos. Su denuncia apunta a la hipocresía

del Consejo de Estado. Actuó en la Guerra de la Independencia y en la dirección del Partido Constitucional contra el Partido Absolutista en Bahía (en el contexto de la crisis del Primer Reinado, de la abdicación y la de la inauguración del período regencial). Su vida política fue narrada por él en sus memorias: Recordações da vida parlamentar do advogado Antônio Pereira Rebouças. Moral, jurisprudência, política e liberdade constitucional y en Recordações da vida patriótica do advogado Antônio Pereira Rebouças. Hebe Maria Matos hace notar "o destaque dado pelo Conselheiro à sua identidade profissional de advogado" (38). 
generalizada en el sentido de que si el tráfico no cesaba era porque no se podía prescindir de la mano de obra africana, con lo cual la solución era traer a los africanos no como esclavos sino como “colonos libres”(Mattos 51-2). Es cierto que políticos de la generación posterior, como Luís Gama (y André Rebouças, hijo del anterior), asumieron posiciones más críticas. También Luís Gama, al igual que Rebouças, era hijo de madre liberta y llegó a ser abogado especialista en derecho civil. Si bien ambos se asumían como "no-blancos" en su lucha contra la discriminación, Luís Gama, desde una línea menos moderada que Rebouças, se declarará abiertamente abolicionista. Según Hebe Maria Mattos, en la memoria brasileña persiste más la figura del abolicionista Luís Gama que la de Antônio Pereira Rebouças, probablemente debido a que este último pertenece a un período que ha sido muchas veces soslayado por la historiografía. Sin embargo, conviene recordar que durante las dos primeras décadas de la monarquía, en ninguna de las diversas luchas y rebeliones sociales y políticas se pone en jaque el derecho de propiedad sobre personas esclavizadas

por todo o conturbado período do Primeiro Reinado e das regências, em um país pesadamente escravista, a metáfora da escravidão como imagem de opressão ou como situação iníqua a ser superada foi constantemente acionada -seja pelo discurso "patriota" da época da independência (o Brasil escravo de Portugal), seja pelo liberal exaltado que clamava por igualdade de direitos entre os brasileiros livres-, mas isso não implicou colocar em xeque o direito de propriedade sobre seres humanos escravizados. (Mattos 2930)

Hemos visto incluso, cómo cuando se produce algún tipo de reclamo proveniente de los descendientes de afrobrasileños libres, que eran mayoría en el Brasil, esto ocurre desde ese "silenciamiento del propio color" puesto que, como se ha dicho, la esclavitud se legitimaba sobre la base del derecho de propiedad y no sobre la categoría de "raza", término que es utilizado oficialmente por primera vez en una estadística brasileña correspondiente al Censo General de 1872, para superponerse a las ya tradicionales categorías de "status/color" (preto, pardo, branco, índio) (Mattos 58-9). Entonces a la discriminación basada en los privilegios de clase-resabios del imperio portugués-, y a la discriminación basada en la propiedad -elitismo liberal-se le suma la discriminación por el color de la piel -como forma de negar los orígenes esclavistas de la mayor parte de la población. Desde este punto de vista, se comprende que "Isaura, por el color de su piel y por haber asimilado la cultura blanca, [sea] recompensada con su libertad y con una posición dentro de la nueva estructura social” (Rosell 170).

Esta ambivalencia con respecto al tema de la esclavitud característica de la intelectualidad brasileña, se advierte en tanto relación discontinua entre el liberalismo aplicado a nivel político y a nivel económico. Por un lado, las ideas liberales iban en contra de la esclavitud pero a su vez la economía brasileña del siglo xix funcionaba en base a la esclavitud. En su célebre artículo “As idéias fora do lugar”, Roberto Schwarz lee este fenómeno como resultado de una arbitrariedad que no logra ser racionalizada debido a la importación acrítica de ideas o conceptos provenientes de Europa, lo que le permite a Schwarz hablar de "ideologías de segundo grado". 
Além dos naturais debates, este antagonismo produziu, portanto, uma coexistência estabilizada -que interesa estudar. Aí a novidade: adotadas as idéias e razões européias, elas podiam servir e muitas vezes serviram de justificação, nominalmente "objetiva”, para o momento de arbítrio que é da natureza do favor. (17, énfasis del autor)

A través de esta institución nacional del “favor”, el sector intermedio de la población -entre ellos los intelectuales- eran protegidos y recompensados por la elite latifundista, con respecto a la cual establecían una dependencia ideológica que no podía ir en contra de sus intereses. Dicho sea de paso, nótese que en la novela de Guimarães, Isaura obtiene su libertad gracias al "favor” de Álvaro, que le "cede” la propiedad sobre sí misma. La lectura del liberalismo brasileño en términos de ideología de segundo grado, tal como la propone Schwarz es relativizada por Emilia Viotti da Costa quien se muestra reacia a ver en esto un mero gesto mimético propio de una cultura colonial y periférica. Según esta autora, las ideas liberales fueron armas ideológicas para alcanzar metas económicas y políticas concretas (Brazilian Empire. Myths and Histories 55-6), y habría que examinar su especificidad dentro de los sucesivos contextos de la historia brasileña (Da Monarquia à República 121-22). Lo cierto es que si en Europa el liberalismo había recibido fuertes críticas desde la perspectiva de las clases trabajadoras, en Brasil la situación es bastante diferente, tal como señala Leslie Bethell en Brazil. Empire and Republic

mientras que en Brasil la falta de una revolución industrial y de un proletariado, junto con la supervivencia de relaciones de producción tradicionales en muchas partes del país hicieron este tipo de críticas si no imposibles, al menos excepcionales. En consecuencia, mientras en Europa el liberalismo estaba a la defensiva, en Brasil permaneció -en las mentes de muchos- como una promesa a ser cumplida. Fue esa esperanza de que la promesa podría ser cumplida la que, en la década de 1870, estaba detrás de la crítica a las instituciones imperiales -una crítica que expresó una creencia ingenua en las cualidades redentoras del progreso, la ciencia y la reforma. (énfasis de la autora, 183)

De algún modo, el personaje de Álvaro es portador de esta creencia ingenua en el progreso y en las reformas de la que habla Bethell. Sus ideas abolicionistas (presentadas en el Capítulo XI) son las de un filántropo “original y excéntrico como un lord inglés” (75) quien decide ponerlas en práctica dentro de su hacienda. Es decir, el abolicionismo como filantropía es ejercido desde un lugar de propietario que se mantiene hasta el final. Se insiste bastante acerca de la excentricidad de Álvaro, que por sus altas y generosas aspiraciones

aprazia-se mais na indagação das altas questões políticas e sociais, em sonhar brilhantes utopias, do que em estudar e interpretar leis e instituições, que pela maior parte, em sua opinião só tinham por base erros e preconceitos os mais absurdos. (75)

Es interesante ver cómo, en el final de la novela, la ruina económica de Leôncio lo lleva a perder esa condición de propietario sobre sus bienes, incluida Isaura, y en ello le va nada menos que la vida. Su muerte es algo más que un suicidio amoroso. A raíz de su pasión descontrolada no logra tomar decisiones racionalmente aceptables para preservar su hacienda, su fortuna, y con ella su identidad. 
Seus desvarios e extravagâncias, e por ultimo sua nefasta e insensata paixão por Isaura, fizeram-lo perder de todo a cabeça, arrojando em um plano inclinado de despesas ruinosas, sem cálculo nem previsão alguma. (154)

Álvaro, en cambio, acrecienta sus bienes, y puede “adquirir” a Isaura legalmente. Si el darle su libertad puede ser considerada otra de sus excentricidades, no obstante, esto le está permitido como propietario, y además habilita otra instancia que es la de pretender, también legalmente, el amor de Isaura a través del matrimonio. Leôncio no logra controlar su pasión y eso le impide ser un propietario “razonable”, ergo, no merece serlo y tampoco merece el amor de Isaura. Ésta, al menos, es mi lectura del desenlace de la novela, aunque lo que me interesa es, más bien, analizar cómo este planteo funciona a lo largo del relato, creando cierta expectativa a nivel de la acción.

En principio, la angelical Isaura parece encarnar “una terrible tentación” para Álvaro -tal como lo es para Leôncio- o al menos eso teme su amigo Geraldo que se erige a sí mismo en voz de la razón y la cordura. Esa voz advierte a Álvaro que sus extravagancias no serán toleradas por la sociedad más allá de ciertos límites, puesto que "quien no respeta las conveniencias e incluso los preconceptos sociales, se arriesga a caer en el descrédito o en el ridículo" (112). Las advertencias de Geraldo son rechazadas por Álvaro con diversos argumentos, algunos un tanto pragmáticos y bastante alejados de su pretendido idealismo.

-És rico, Álvaro, e a riqueza te dá bastante independência, para poderes satisfazer os teus sonhos filantrópicos e os caprichos de tua imaginação romanesca. Mas tua riqueza, por maior que seja, nunca poderia reformar os prejuízos do mundo, nem fazer com que essa escrava, a quem segundo todas as aparências quererias ligar o teu destino, fosse considerada, e nem mesmo admitida nos círculos da alta sociedade...

- [...] Demais, enganas-te completamente, meu Geraldo. O mundo corteja sempre o dinheiro, onde quer que ele se ache. O ouro tem um brilho, que deslumbra, e apaga completamente essas pretendidas nódoas de nascimento. Não nos faltarão nunca, eu te afianço, o respeito, nem a consideração social, enquanto nos não faltar o dinheiro (11213)

No obstante -tal como le hace ver Geraldo- la riqueza de Álvaro no puede en principio superar el obstáculo de que Isaura sea propiedad ajena y de que Leôncio no esté dispuesto a venderla. Es ahí donde Álvaro corre peligro de ser víctima de una "ciega pasión” que lo llevaría a cometer actos calificables de "burlesco desatino” y de "locura incalificable”, en suma "ridículas extravagancias” (120) contra el derecho de propiedad. Álvaro, que en principio se resiste a devolver a Isaura a su legítimo dueño, argumenta que los motivos que lo impulsan y las cualidades propias de Isaura ennoblecen su procedimiento y lo justifican ante su conciencia. Ni la propia Isaura, que como "esclava sumisa sabe reconocer su lugar [...] sin rebelarse, sin dejar jamás de ser emocionalmente esclava” (Soares Fonseca), logra disuadirlo haciéndole ver lo inconveniente de sus propósitos.

Por piedade, Isaura, não me martirizes mais com essa maldita palavra, que constantemente tens nos lábios. Escrava tu!... não o és, nunca o foste, e nunca o serás. Pode acaso a tirania de um homem ou da sociedade inteira transformar em um ente vil, e votar à escravidão 
aquela que das mãos de Deus saiu um anjo digno de respeito e adoração de todos? Não, Isaura; eu saberei erguer-te ao nobre e honroso lugar o que o céu te destinou, e conto com a proteção de um Deus justo, porque protejo um dos seus anjos. (122, énfasis mío)

En otras palabras, la condición de esclava de Isaura queda “borrada” por su condición de “ángel” y cualquier empresa que Álvaro lleve a cabo para protegerla contará con el aval de la la justicia divina. Álvaro ya había utilizado estos argumentos frente a su amigo Geraldo, aunque acompañados de otros -mucho más a tono con el discurso de la modernidad- en los que "Dios” es reemplazado por “civilización”.

A escravidão em si mesma já é uma indignidade, uma úlcera hedionda na face da nação, que tolera e protégé. Por minha parte, nenhum motivo enxergo para levar a esse ponto o respeito por un preconceito absurdo, resultante de um abuso, que nos desonra aos olhos do mundo civilizado. Seja eu embora o primeiro a dar esse nobre exemplo, que talvez será imitado. Sirva ele ao menos de um protesto enérgico e solene contra uma bárbara e vergonhosa instituição. (112)

Si el liberalismo brasileño, o la elite intelectual que lo representa, ve frenada su tan ansiada entrada a la modernidad y al mundo civilizado, es por la persistencia de instituciones como la esclavitud y por los resabios del viejo orden patriarcal defendido por muchos hacendados, particularmente en el estado de Minas Gerais, de donde proviene Bernardo Guimarães. Vemos entonces cómo en la novela se confirma este antiesclavismo figurado que no llega a ser abolicionismo, sugerido por Rosell. Es evidente que no hay cabida para plantear una nueva legalidad que destierre la esclavitud de la sociedad, por encima de las iniciativas individuales de propietarios que piensen como Álvaro, o que sigan su ejemplo. También como resabio del viejo orden puede leerse la garantía de una justicia divina, que permita a Álvaro ejercer su protección sobre Isaura para rescatarla de la esclavitud. La angelicalidad de Isaura despliega en torno suyo varios imaginarios. Por un lado, un imaginario religioso: por su “pureza de ángel”, por su “resignación de mártir”, y porque las iniciativas de Álvaro constituyen “una misión santa recibida del cielo” (156) frente a Leôncio que encarnaría nada menos que a Lucifer (124). Por otro lado, su aspecto angelical se funde con su apariencia de mujer blanca educada y eso le permite ser aceptada momentáneamente, y admirada, por la sociedad de Recife a quienes oculta su condición de esclava, que bajo tales apariencias pasa desapercibida ante todos. Al descubrirse la verdad, surge el desconcierto entre algunos de los concurrentes al baile, donde esta escena tiene lugar:

-É assombroso! Quem diria, que debaixo daquela figura de anjo estaria oculta uma escrava fugida!

-E também quem nos diz, que no corpo da escrava não se acha asilada uma alma de anjo?... (97)

De modo que si se pone en duda que merezca su condición de esclava, no es tanto porque la esclavitud en sí misma resulte condenable, sino porque sus apariencias la eximen de serlo. Recordemos que apenas conoce a Álvaro, Isaura piensa que el suyo sería un amor 
imposible ya que tarde o temprano se vería obligada a confesar su condición porque "una esclava que procede con sinceridad y lealtad, puede al menos ser estimada”(85). Sin embargo, la percepción que de sí misma tiene va cambiando a medida que empieza a verse a través de los ojos de Álvaro y llega a olvidar momentáneamente su situación.

Cândida e modesta como era, nem por isso Isaura deixava de ter consciência do quanto valia. Vendo-se o objeto do amor de um jovem de espírito elevado, e dotado de tão nobres e brilhantes qualidades como Álvaro, ainda mais se confirmou na idéia que de si mesma fazia. (89)

-Estou convencida de que sou digna do amor de Álvaro, se-não, ele me não amaria; e se sou digna de seu amor, por que não serei de me apresentar no seio da mais brilhante sociedade? (90)

Es entonces que decide asistir al baile de sociedad en Recife, gracias a que Álvaro logra convencerla argumentando que "una señora joven y hermosa como ella, que oculta sus encantos en soledad, comete un crimen contra los ojos del Creador, que dio forma a su belleza para ser vista, admirada y adorada” (71). Esa belleza angelical de Isaura parece constituir su mejor “dote” para que Álvaro la acepte incondicionalmente. Eso es lo que da a entender ante los reparos de Geraldo con respecto a esa mujer desconocida.

-[...] Mas dize-me cá, meu Álvaro; ese anjo, fada, deusa, mulher ou o que quer que seja, não te disse donde veio, de que família é, se tem fortuna, etc., etc., etc.

-Pouco me importo com essas cousas e poderia responder-te que veio do céu, que é da família dos anjos, e que tem uma fortuna superior a todas as riquezas do mundo: uma alma pura, nobre e inteligente, e uma beleza incomparável. Mas sempre te direi, que o que sei de positivo a respeito dela, é que veio do Rio Grande do Sul em companhia de seu pai, de quem é ela a única família; que seus meios são bastantemente escassos, mas que em compensação ela é linda como os anjos [...]. (68-9)

Entiendo que esa angelicalidad de Isaura está estrechamente relacionada con las virtudes de pureza y castidad en base a las cuales se constituye el modelo del ángel del hogar, tan caro a la literatura de la época, y que sirve como instrumento para "regular" la sexualidad del varón en vistas al matrimonio. En este sentido, Nancy Armstrong destaca la obsesión con la pureza sexual en las novelas del siglo xIX, particularmente por su dimensión retórica. Según esta autora, el deseo femenino se convierte de algún modo en mera operación retórica de la transformación del varón, de bruto competitivo en padre benevolente” (56). El deseo femenino en realidad estaría supeditado, en este contexto, al propósito de encauzar la sexualidad del varón dentro del ámbito del hogar y de la sexualidad (re)productiva. ${ }^{7}$

\footnotetext{
${ }^{7}$ En este sentido, el análisis de Nancy Armstrong tiene incluso mayores alcances al plantear que: "Domestic fiction mapped out a new domain of discourse as it invested common forms of social behavior with the emotional values of women. Consequently, these stories of courtship and marriage offered their readers a way of indulging, with a kind of impunity, in fantasies of political power that were the more acceptable because they were played out within a domestic framework where legitimate monogamy -and thus the subordination of female to male- would ultimately be affirmed.
} 
Por su belleza y virtudes Isaura “merece” el amor de un hombre capaz de controlar sus pasiones para permitirse finalmente tomarla como esposa. Álvaro logra respetarla incluso sabiendo que es esclava. Leôncio, por el contrario estaba dispuesto a usar la violencia como recurso extremo para poseer a Isaura, y a dilapidar su fortuna ofreciendo recompensas a quien, como Martinho, le diera información sobre su paradero. Pero ya hemos visto que Leôncio pagará cara la falta de control de sus pasiones. Uno y otro encarnan diferentes modelos masculinos en relación con un tipo de sexualidad que aparece regulada por los códigos de conducta de la época. Por su parte, Isaura, en tanto heroína romántica , se reconoce como un sujeto que ama -aunque no sea libre- y eso le permite oponerse al deseo de Lêoncio quien le ofrece la libertad a cambio de que ceda a sus deseos. Para sorpresa suya, ella le responde que el corazón de una esclava es libre y no es posible gobernar sus afectos (63). Si, por el contrario, el romance entre Isaura y Álvaro se cumple felizmente es porque ambos controlan sus deseos y pasiones. Asimismo, el carácter contractual de las escenas finales de la novela encuadra los hechos dentro de una legalidad aceptada y aceptable para las convenciones de la época. En principio, como propietario legítimo, Álvaro toma posesión de Isaura en tanto esclava, luego le otorga el "favor" de su libertad, y finalmente se propone "tomar posesión” de ella dentro de la legalidad del matrimonio. Obviamente, esta segunda “toma de posesión” no sería tal, puesto que Isaura decide unirse a Álvaro, desde su nuevo estatus de mujer libre, incluida la bendición de su padre. Sin embargo, esta dimensión contractual puede ser examinada bajo ciertas perspectivas críticas que examinan lo que se denomina "el contrato sexual”, en el cual -según destaca Armstrong- persisten las contradicciones propias del "contrato social” rousseuniano como construcción ficcional.

The idea of free individuals voluntarily entering into a contract with one another was obviously impossible to realize in a state where people were already born into different classes and status groups that denied them an opportunity to make the kind of choice which the contract specified as necessary for its success. (36-7)

Sin embargo, es precisamente en la idea del "contrato sexual” tal como aparece planteado en estas novelas del siglo XIX, donde parecen diluirse estas contradicciones en una resolución con final feliz. En el mismo sentido, puede leerse esa operación retórica por la que el deseo de la mujer aparece sublimado en aras del matrimonio, que le brindará protección y dependencia económica. Ya se ha hecho referencia al análisis de Carol Pateman acerca de cómo funciona la lógica del contrato social para responder a la paradoja que la esclavitud suscita en el marco de la modernidad. Desde una perspectiva filosófica y jurídica, Carol Pateman examina también el contrato sexual, cuya historia resultaría fundamental para una comprensión del patriarcado moderno ${ }^{8}$ especialmente porque

In this way, domestic fiction could represent an alternative form of political power without apperaring to contest the distribution of power that it represented as historically given"(29). ${ }^{8}$ En el capítulo 2 de su libro, Pateman analiza minuciosamente el uso del término "patriarcal” desde diversas perspectivas críticas y las confusiones que suelen generarse. Me interesa rescatar su idea de que "Modern society is structured by universal, conventional bonds of contract, not the particular, 
Private domestic relations also originate in a contract -but the meaning of the marriage contract, a contract between a man and a woman, is very different from the meaning of contracts between men in the public sphere. The marriage contract reflects the patriarchal ordering of nature embodied in the original contract. A sexual division of labour is constituted through the marriage contract. (118)

En síntesis, la resolución del romance implica un aceptamiento de todos los contratos. Aun a pesar de Leôncio, que endeudado no tiene más alternativas que aceptar un contrato en los términos que establece quien tiene el poder económico, la libertad de Isaura es negociada entre ambos hombres. Rápidamente y sin correr mayores riesgos, Isaura-como mujer "libre" y con la bendición de su padre- delega su flamante libertad en el futuro matrimonio con Álvaro, el candidato que reúne todas las condiciones. La decisión filantrópica de Álvaro descansa en dos pilares: por un lado, un discurso moderno de ideas liberales progresistas que lo pone en riesgo de parecer abolicionista y excéntrico, y por otro, un discurso a tono con el viejo orden conservador que enmarca su empresa de liberar a Isaura no en el nuevo orden secular que marca el progreso, sino bajo la garantía de una justicia divina a la que se invoca en todo momento. Ambos discursos respaldan el derecho de propiedad, pero en la medida en que éste se ve amenazado por la profundización de las ideas liberales, aparece "extrapolado" el reaseguro de la justicia divina "gracias a la cual” finalmente Isaura obtiene su libertad a la que se había hecho merecedora por sus 'virtudes y talentos'. En tanto mulata “blanqueada” por su color(raza) y por su educación, merece ser públicamente aceptada en la sociedad de la época y en tanto mujer merece un matrimonio conveniente por su pureza de ángel — propia de una mujer "blanqueada” y educada—. De este modo, ambos órdenes, el público y el privado, se reafirman y consolidan mutuamente.

\section{BiBLIOGRAFÍA}

Anderson, Benedict. Imagined Commnuities: Reflections on the Origin and Spread of Nationalism. New York: Verso, 1991.

Armstrong, Nancy. Desire and Domestic Fiction. A Political History of the Novel. New York/Oxford: Oxford University Press, 1987.

Aderaldo, José. A Literatura Brasileira. Origens e Unidade (1500-1960). Vol.1. São Paulo, 1999.

Bethell, Leslie (ed.) Brazil. Empire and Republic. 1822-1930. Cambridge: Cambridge University Press, 1989.

Candido, Antonio. Formação da Literatura Brasileira (Momentos decisivos). Vol. 2. (1836-1880). São Paulo: Martins, 1969.

Coutinho, Afrânio. A Literatura No Brasil. [1968]. Vol. 3. Era Romántica, 3ra. ed. Rio de Janeiro/Niterói: José Olimpo Editora-Universidad Federal Fluminense,1986.

ascriptive bonds of kinship. In the modern world, 'kinship' is transformed into the 'family', which has its own principle of association and its own social location in the private sphere, separate from the public 'civil' society. (30) 
Gómez de Avellaneda y Arteaga, Gertrudis. Sab. Madrid: Cátedra, 1997.

Guimarães, Bernardo. A escrava Isaura. São Paulo: Edições Melhoramentos, 1973.

Mattos, Hebe Maria. Escravidão e cidadania no Brasil monárquico. Rio de Janeiro: Jorge Zahar Editor, 2000.

Norwood, Andrews. “A Modern Classification of Bernardo Guimarães’ Prose Narratives”. Luso-Brazilian Review 3/2 (1966): 59-82.

Pateman, Carol. The Sexual Contract. Stanford, California: Stanford University Press, 1988.

Reis, Maria Firmina dos. Ursula. Rio de Janeiro: Presença, 1988.

Schwarz, Roberto. “As idéias fora do lugar.” Ao Vencedor as Batatas. Forma literária e processo social nos inícios do romance brasileiro. São Paulo Livraria Duas Cidades, 1977. 13-28.

Rosell, Sara V. La novela antiesclavista en Cuba y Brasil, siglo XIX. Madrid: Pliegos, 1997.

Skidmore, Thomas E. "Racial Ideas and Social Policy in Brazil”. The Idea of Race in Latin America, 1870-1940. Richard Graham, ed. Austin: University of Texas Press, 1990. 7-36.

Soares Fonseca, Maria Nazareth. "Fada? Anjo? Deusa? Escrava”. http:// www.geocities.com/Athens/Olympus/3583/isaura.htm, 09/25/01.

Sommer, Doris. Foundational Fictions: The National Romances of Latin America. Berkeley: University of California Press, 1991.

Villaverde, Cirilo. Cecilia Valdés; o, La loma del Ángel. New York: Las Américas Pub. Co, 1964.

Viotti da Costa, Emília. Brazilian Empire. Myths \& Histories. Revised Edition. Chapel Hill y London: University of North Carolina Press, 2000.

Da Monarquia à República: momentos decisivos. São Paulo: Brasiliense, 1985. 